\title{
Systematic review of neuropsychological instruments used in subthalamic nucleus deep brain stimulation in Parkinson's disease patients
}

\author{
Eduarda Naidel Barboza e Barbosa1 ${ }^{1}$ Helenice Charchat-Fichman²
}

\begin{abstract}
In addition to drug treatment, surgical intervention represents an alternative to PD patients with motor deficits. The most common intervention is subthalamic nucleus deep brain stimulation (STN-DBS). It is extremely important to perform a neuropsychological assessment in patients with STN-DBS, not only to identify losses related to the disease, but also to compare influence on cognition both pre and postoperatively. Objective: the objective of this systematic review was to investigate the instruments frequently used in studies related to STN-DBS in PD patients. Methods: articles were retrieved from Medline/ Pubmed databases published in the 2007-2017 period using PRISMA criteria. Results: after analyzing 27 articles, the absence of a specific evaluation protocol for PD with STN-DBS was evident. Conclusion: non-motor symptoms are not given due importance in neuropsychological assessments. It is crucial to acknowledge that these symptoms have a major impact on the quality of life of patients. Greater engagement in assessing these aspects is required, in order to bridge the gaps in research. Key words: Parkinson's disease, deep brain stimulation, neuropsychological instruments, neuropsychological assessment.
\end{abstract}

REVISÃO SISTEMÁTICA DE INSTRUMENTOS NEUROPSICOLÓGICOS USADOS EM PACIENTES COM DOENÇA DE PARKINSON E ESTIMULAÇÃO CEREBRAL PROFUNDA NO NÚCLEO SUBTALÂMICO

RESUMO. Além do tratamento medicamentoso, a intervenção cirúrgica é uma alternativa aos pacientes com DP com déficits motores. A mais comum é a estimulação cerebral profunda do núcleo subtalâmico (ECP-NST). É extremamente importante realizar uma avaliação neuropsicológica em pacientes com ECP-NST, não apenas para identificar perdas relacionadas à doença, mas também para comparar a influência na cognição em cirurgias pré e pós-operatórias. Objetivo: esta revisão sistemática teve como objetivo investigar os instrumentos frequentemente utilizados em pesquisas relacionadas a ECP-NST em pacientes com DP. Métodos: Os artigos foram coletados nas bases de dados Medline / Pubmed publicadas no período de 2007-2017, utilizando os critérios do PRISMA. Resultados: após a análise de 27 artigos, percebeu-se a ausência de um protocolo de avaliação específico para a DP com ECP-NST. Conclusão: os sintomas não motores não tem recebido a devida importância na avaliação neuropsicológica. É fundamental reconhecer que eles representam grande influência na qualidade de vida dos pacientes. É necessário maior engajamento na avaliação desses aspectos, a fim de preencher as lacunas das pesquisas. Palavras-chave: doença de Parkinson, estimulação cerebral profunda, instrumentos neuropsicológicos, avaliação neuropsicológica.

Parkinson's disease (PD) is considered the 1 second-most-common neurodegenerative disease, preceded only by Alzheimer's disease (AD). ${ }^{1,2}$ PD's motor characteristics are much better known than its non-motor ones, but patients also have functional impairment. ${ }^{1,3-5}$ When PD was first described, cognition was believed to be preserved, but current research ${ }^{6,7}$ reports cognitive decline. Besides drug treatment, surgical intervention can be

This study was conducted at the Pontifical Catholic University of Rio de Janeiro, RJ, Brazil.

'Master, Pontifical Catholic University of Rio de Janeiro (PUC-Rio), Rio de Janeiro, RJ, Brazil. 2Professor, Pontifical Catholic University of Rio de Janeiro (PUC-Rio), Rio de Janeiro, RJ Brazil.

Eduarda Naidel Barboza e Barbosa. Rua Marquês de São Vicente, 225 / Gávea - 22451-900 Rio de Janeiro RJ - Brazil. E-mail: psienbb@gmail.com

Disclosure: The authors report no conflicts of interest.

Received February 26, 2018. Accepted in final form April 06, 2019.

(c) $\mathbf{B Y}$ 
used in some cases. One of these methods is deep brain stimulation (DBS), consisting of electrical stimulation of subcortical structures. The main objective of DBS is motor control of symptoms; however, the stimulated areas are also potentially able to stimulate some cognitive functions secondarily. ${ }^{8}$

Studies usually promote cognitive screening in patients to characterize the sample and identify the impairments to be analyzed. However, comparing cognitive data from different populations and based on different tests can produce conflicts in the literature, mainly because some screening instruments do not provide the sensitivity to assess cognitive functioning sufficiently ${ }^{5}$, while others employ different versions of the same test or use non-standard tasks.

The objective of this review was to learn about and understand the use of some instruments used in studies of PD patients with STN-DBS and to relate these findings with the literature in general. The search included articles published between January 2007 and January 2017, based on The Preferred Reporting Items for Systematic Review and Meta-Analyses (PRISMA) criteria.

\section{METHODS}

The systematic review is a type of scientific study that aims to gather, critically evaluate and produce a synthesis of multiple primary studies. ${ }^{9}$

\section{Bibliographic survey}

We designed a systematic review of the literature according to the Preferred Reporting Items for Systematic Review and Meta-Analyzes (PRISMA) criteria. The following terms were used: "Deep Brain Stimulation", "DBS", "Cognitive Functions" and "Parkinson Disease" with the Boolean operator "AND". We selected scientific papers published in English between January 2007 and January 2017, involving comparative clinical trials in humans, from the Medline/Pubmed databases. Articles published before 2007, systematic reviews, case studies, book chapters and studies using animals were excluded.

\section{Study selection}

Initially, this method retrieved 345 studies (Figure 1). To refine the search, the following topics were selected: "Parkinson's Disease", "Subthalamic Nucleus", "Deep Brain Stimulation", "DBS", “Cognition” (263), published on the Medline/Pubmed database (223) between 2007 and 2017 (195). From the material retrieved, we examined titles and abstracts for studies involving only human clinical trials (66). Literature reviews and case studies were excluded, as were articles with problems in

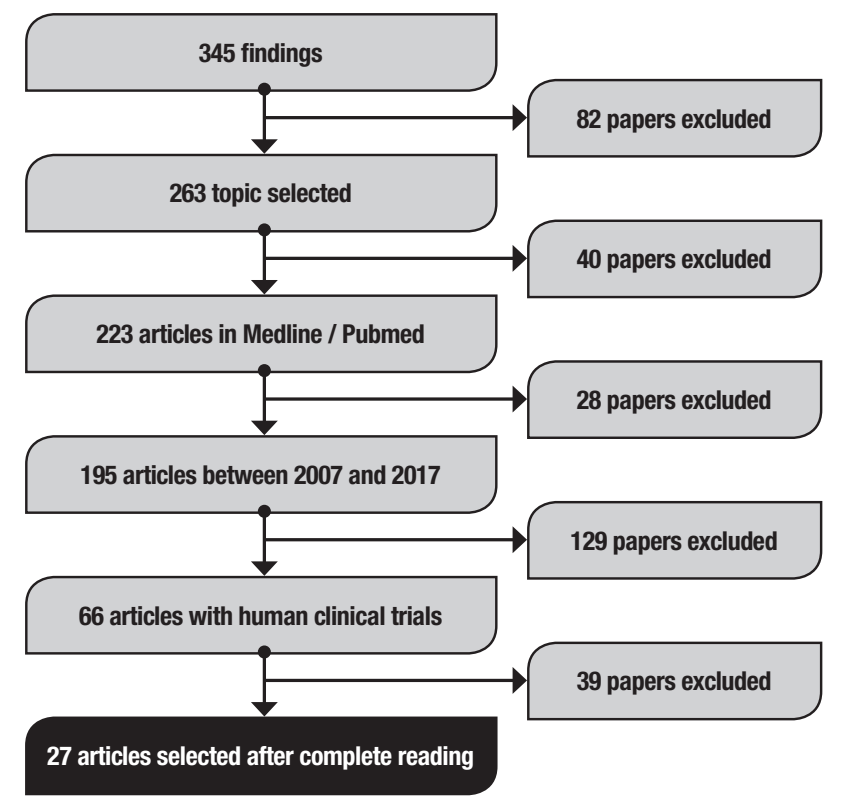

Figure 1. Article search flow diagram.

the methodology, such as absence of (a) inclusion and exclusion criteria, (b) complete assessment protocol and (c) pre or post-surgery assessment (27). The researchers selected the articles independently: considering suitable studies that (a) evaluated PD patient cognition with STN-DBS; (b) reported the instruments and domains evaluated; and (c) presented pre and post-surgical results.

\section{RESULTS}

The final list of articles included based on the search criteria in order of year, with Objectives and Results (Table 1), a list of instruments with quantity, separated by domains (Table 2) and a list of instruments used before and after DBS implantation to assess the cognitive aspects of the patients (Table 3 ) are given below.

\section{DISCUSSION}

A total of 61 (sixty-one) instruments were used to evaluate different aspects of patients, including batteries, subtests, scales and tasks (Table 2). These can be ordered from the most evaluated to least used, as follows: executive functions (14), global cognitive functioning (10) and mood (10), memory (9), language (5), psychiatric symptoms (3) and sensory-motor coordination (3), patient quality of life (2) and visuoconstructive skills (2) and attention (1), perception (1) and activities of daily living (1). Early in the onset of symptoms, $24 \%$ of patients presented cognitive impairment, especially memory problems, and executive function disorders: selective attention, flexibility in reasoning and planning capacity, visuoconstructive skills and naming ability. ${ }^{9}$ 


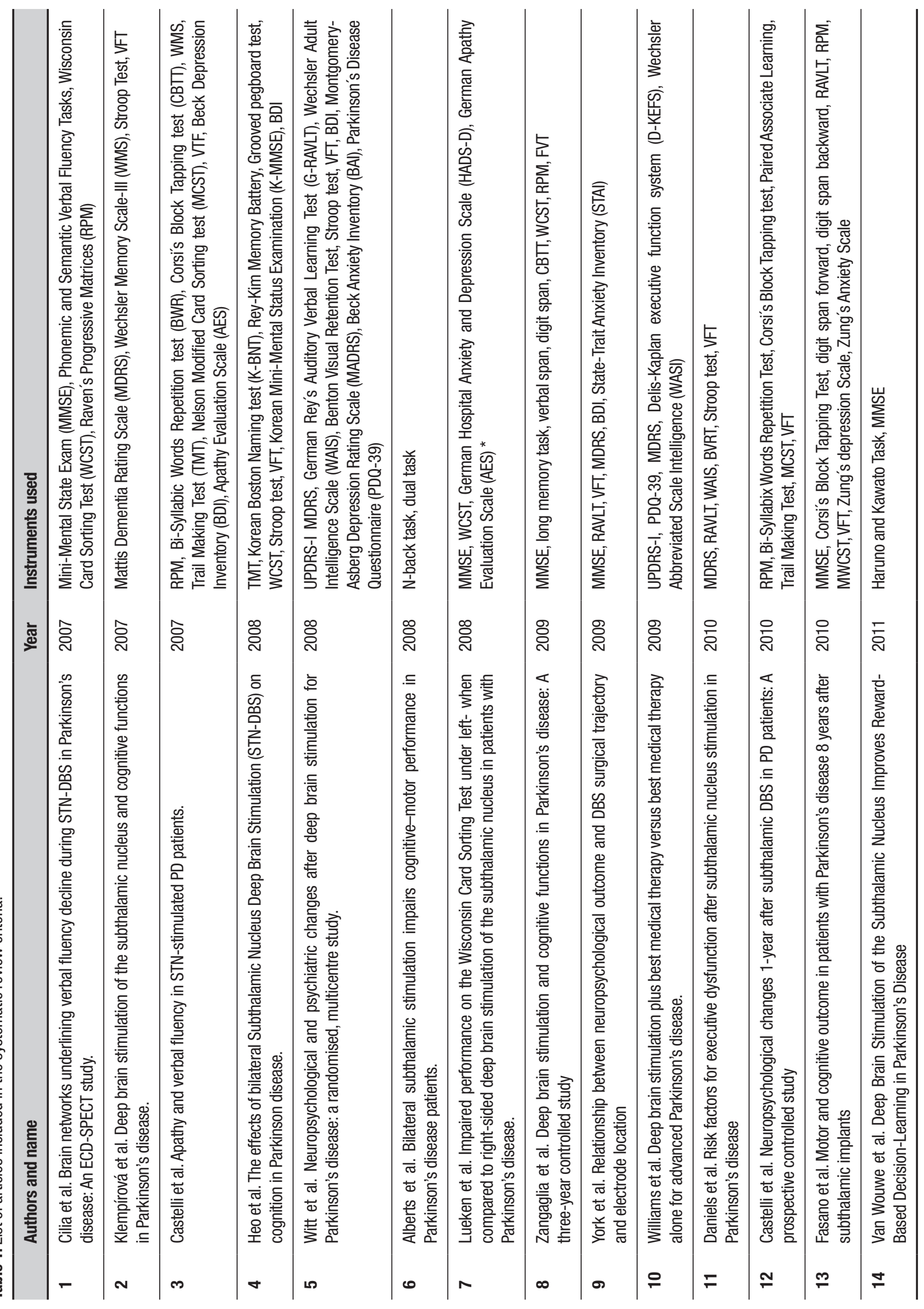




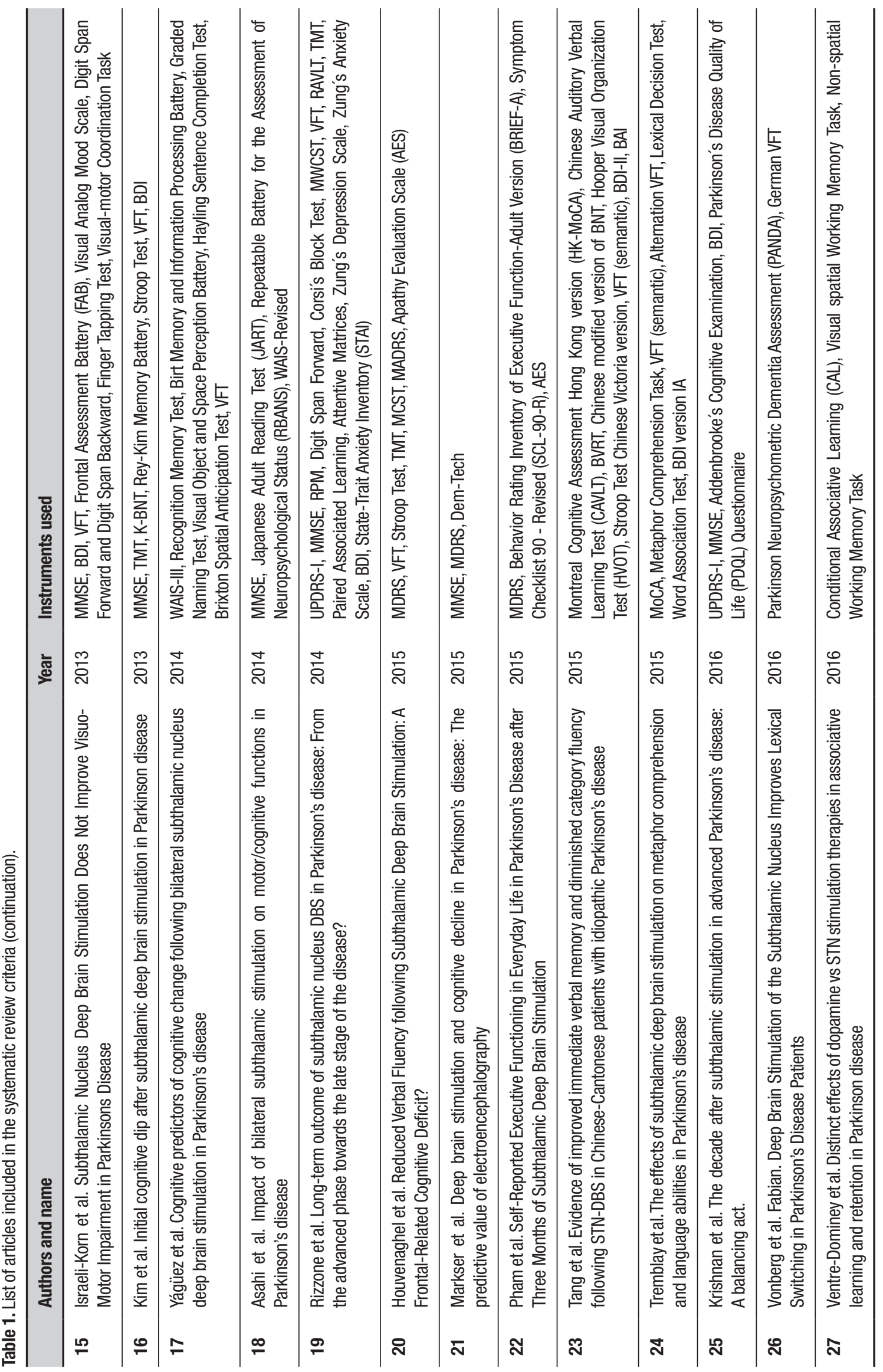


Table 2. List and frequency of instruments used by domain.

\begin{tabular}{|c|c|c|c|}
\hline $\mathbf{N}^{0}$ & Domains Assessed & Instruments & $\mathrm{N}^{0}$ of articles \\
\hline 1 & Activities of Daily Living & UPDRS-I Non-Motor Experiences & 3 \\
\hline \multirow{2}{*}{2} & \multirow{2}{*}{ PD Quality of Life } & Parkinson's Disease Questionnaire (PDQ-39) & 2 \\
\hline & & Parkinson's Disease Quality of Life (PDQL) & 1 \\
\hline \multirow{10}{*}{3} & \multirow{10}{*}{ Global Functioning } & Mini-Mental State Exam (MMSE)* & 14 \\
\hline & & Mattis Dementia Rating Scale (MDRS) & 8 \\
\hline & & Raven's Progressive Matrices (RPM) & 6 \\
\hline & & Wechsler Adult Intelligence Scale (WAIS-III)* & 4 \\
\hline & & Montreal Cognitive Assessment (MoCA)* & 2 \\
\hline & & Addenbrooke's Cognitive Examination & 1 \\
\hline & & Japanese Adult Reading Test (JART) & 1 \\
\hline & & Repeatable Battery for the Assessment of Neuropsychological Status (RBANS) & 1 \\
\hline & & Dem-Tech & 1 \\
\hline & & Parkinson Neuropsychometric Dementia Assessment (PANDA) & 1 \\
\hline \multirow{3}{*}{4} & \multirow{3}{*}{ Psychiatric Symptoms } & Brief Psychiatric Rating Scale (BPRS) & 1 \\
\hline & & Visual Analogue Mood Scale & 1 \\
\hline & & Symptom Checklist 90 - Revised (SCL-90-R) & 1 \\
\hline \multirow{14}{*}{5} & \multirow{14}{*}{ Executive Functioning } & Verbal Fluency Tasks - Semantic* & 19 \\
\hline & & Verbal Fluency Tasks - Phonemic* & 17 \\
\hline & & Wisconsin Cards Sorting Test (WCST)* & 9 \\
\hline & & Stroop Test* & 7 \\
\hline & & Trail Making Test (TMT)* & 6 \\
\hline & & Digit Span Forward and Backward & 5 \\
\hline & & Frontal Assessment Battery (FAB) & 1 \\
\hline & & Behavior Rating Inventory of Executive Function - Adult Version (BRIEF-A) & 1 \\
\hline & & Hayling Sentence Completion Test & 1 \\
\hline & & Brixton Spatial Anticipation Test & 1 \\
\hline & & Haruno and Kawato Task (2006) ${ }^{\star \star}$ & 1 \\
\hline & & Delis-Kaplan Executive Function System (D-KEFS) & 1 \\
\hline & & $\mathrm{N}$-back and dual task & 1 \\
\hline & & Visual Spatial and Non-spatial Working Memory Task & 1 \\
\hline
\end{tabular}


Table 2. List and frequency of instruments used by domain (continuation).

\begin{tabular}{|c|c|c|c|}
\hline $\mathbf{N}^{0}$ & Domains Assessed & Instruments & $\mathrm{N}^{0}$ of articles \\
\hline \multirow{9}{*}{6} & \multirow{9}{*}{ Memory } & Rey's Auditory Verbal Learning Test (RAVLT)* & 6 \\
\hline & & Corsi's Block Tapping Test (CBTT) & 5 \\
\hline & & Paired Associate Learning (Wechsler Memory Scale) & 4 \\
\hline & & Bi-Syllabic Words Repetition test (BWR) & 2 \\
\hline & & Rey-Kim Memory Battery & 2 \\
\hline & & Recognition Memory Test & 1 \\
\hline & & Birt Memory and Information Processing Battery & 1 \\
\hline & & Long Memory Task and Verbal Span & 1 \\
\hline & & Conditional Associative Learning $(\mathrm{CAL})^{\star \star}$ & 1 \\
\hline \multirow{5}{*}{7} & \multirow{5}{*}{ Language } & Boston Naming Test (BNT)* & 3 \\
\hline & & Graded Naming Test & 1 \\
\hline & & Metaphor Comprehension Task & 1 \\
\hline & & Lexical Decision Test & 1 \\
\hline & & Word Association Test & 1 \\
\hline 8 & Attention & Attentive Matrices & 1 \\
\hline 9 & Perception & Incomplete Letters and Object Decision tasks (Visual Object and Space Perception Battery) & 1 \\
\hline \multirow{2}{*}{10} & \multirow{2}{*}{ Visuospatial Skills } & Benton Visual Retention Test & 3 \\
\hline & & Hooper Visual Organization Test (HVOT) & 1 \\
\hline \multirow{10}{*}{11} & \multirow{10}{*}{ Mood } & Beck Depression Inventory (BDI) & 10 \\
\hline & & Apathy Evaluation Scale (AES)* & 4 \\
\hline & & State-Trait Anxiety Inventory (STAl) & 2 \\
\hline & & Zung's Anxiety Scale & 2 \\
\hline & & Beck Anxiety Inventory (BAl) & 2 \\
\hline & & Zung's Depression Scale & 2 \\
\hline & & Montgomery-Asberg Depression Rating Scale (MADRS) & 2 \\
\hline & & Hospital Anxiety and Depression Scale (HADS-D)* & 1 \\
\hline & & Snaith-Hamilton Pleasure Scale & 1 \\
\hline & & Bech-Rafaelsen Mania Scale & 1 \\
\hline \multirow{3}{*}{12} & \multirow{3}{*}{$\begin{array}{l}\text { Sensory-Motor } \\
\text { Coordination }\end{array}$} & Grooved Pegboard Test & 1 \\
\hline & & Visual-motor Coordination Task & 1 \\
\hline & & Finger Tapping Test & 1 \\
\hline
\end{tabular}


What justifies the most evaluated domains in the selected articles? PD patients with mild cognitive impairment (MCI), compared with PD patients without $\mathrm{MCI}$, have significantly poorer performance on almost all cognitive domains: executive functions, attention, memory, and language. ${ }^{7}$ One in three patients with PD has cognitive impairment at the time of, or shortly after, diagnosis, progressively worsening or even causing dementia in the advanced stages. ${ }^{6}$ However, cognitive alterations are common even in non-PD patients. ${ }^{10} \mathrm{Cog}$ nitive impairment increases the risk of dementia, by 1.7 to 5.9, and early detection and identification of dementia risk is a major challenge due to the heterogeneity of patient profiles. ${ }^{6}$ The prevalence of dementia in PD is 24 to $31 \%,{ }^{11}$ thus, evaluating the PD patient in a global and continuous way is the best path for monitoring the evolution of the effects of the disease. Comorbidity with dementia can be justified when we consider the ascending involvement of the brainstem to the cortical area. Microscopic modifications may be incorporated into its pathophysiology, including losses of neurons, gliosis, while surviving neurons may contain Lewy bodies. The loss of neurons markedly affects the substantia nigra, although it is not restricted to it. The damage also affects the aminergic nuclei of the brainstem, Meynert's basal nucleus, hypothalamic nuclei and olfactory bulb. ${ }^{12}$ For this reason, it is essential to investigate the effects of surgery, such as STN-DBS, on the different aspects of a subject with $\mathrm{PD}$.

The MMSE was the most used instrument ${ }^{13-25}$ for assessing global cognitive functioning among the selected studies. It was followed by the MDRS ${ }^{17,24,26-31}$ and RPM. ${ }^{13,16,18,32}$ The MMSE has several favorable qualities such as fast administration, easy interpretation for use during medical consultation; patient acceptability; cultural independence; and both language and education, which makes it easier to reproduce in different studies and provides similar performance among examiners. In contrast, the instrument is influenced by subjective or non-standardized application and interpretation by professionals. Screening tests, such as these, known and widely used, are highly dependent on a minimal educational level and have low sensitivity and specificity. ${ }^{33}$ Thus, an evaluation protocol containing only this instrument to evaluate global cognitive functioning would have little range in terms of the patient's cognitive loss.

Several instruments were used to assess the EF of PD patients with STN-DBS, but the most recurrent were verbal fluency tasks, both semantic and phonemic, ${ }^{13,14,16-18,20,21,23,26,27,29,30,32,34,35,37,38}$ followed by the
Table 3. Instruments most used pre and post-DBS.

\begin{tabular}{|c|}
\hline Instruments \\
\hline - Parkinson's Disease Questionnaire (PDQ-39) \\
\hline - Parkinson's Disease Quality of Life (PDQL) \\
\hline - Mini-Mental State Exam (MMSE)* \\
\hline - Mattis Dementia Rating Scale (MDRS) \\
\hline - Raven's Progressive Matrices (RPM) \\
\hline - Symptom Checklist 90 - Revised (SCL-90-R) \\
\hline - Verbal Fluency Tasks - Semantic* \\
\hline - Verbal Fluency Tasks - Phonemic* \\
\hline - Wisconsin Cards Sorting Test (WCST)* \\
\hline - Stroop Test* \\
\hline - Trail Making Test (TMT)* \\
\hline - Digit Span Forward and Backward \\
\hline - Rey's Auditory Verbal Learning test (RAVLT)* \\
\hline - Corsi's Block Tapping test (CBTT) \\
\hline - Rey-Kim Memory Battery \\
\hline - Boston Naming Test (BNT)* \\
\hline - Attentive Matrices \\
\hline - Incomplete Letters and Object Decision tasks \\
\hline - (Visual Object and Space Perception Battery) \\
\hline - Benton Visual Retention Test \\
\hline • Beck Depression Inventory (BDI) \\
\hline - Apathy Evaluation Scale (AES)* \\
\hline - State-Trait Anxiety Inventory (STAI) \\
\hline - Beck Anxiety Inventory (BAl) \\
\hline - Grooved Pegboard Test \\
\hline
\end{tabular}

WCST. ${ }^{13-16,18,23,30,32,34}$ These tasks, in particular, underwent different adaptations in each article. Evaluating EFs is a major challenge, as is defining the concept. In general, it is understood as abilities that involve planning, organization, flexibility, monitoring and inhibitory control, ${ }^{39}$ presenting an adaptive value for the subject, since their performance on activities related to personal, professional and other domains also become impaired. ${ }^{40}$ Executive dysfunction is not always associated with memory, language or visuospatial skill impairment, among others, but rather a functional decline that can often be assessed based on self-report or a caregiver and/or family member informant. In patients with PD, it is a predictor of impairment, leading to ADL deficits. ${ }^{8}$

A number of studies ${ }^{14,16-18,21,23,27,29,32,34,35,36,41}$ used 9 different types of tests to evaluate memory, predominantly 
the RAVLT (memory and verbal learning) and CBTT (memory and visual learning). The neocortex and striatum are structures involved in implicit memory processing and dopamine is the neurotransmitter involved in the formation of these memories. ${ }^{2,42}$ Therefore, with the dopaminergic deficit and degeneration of the basal nuclei involved in PD pathology, this processing and pre-activation of the priming and learning procedures are impaired. In the early stages of PD, there are deficits in the implicit learning of new tasks. Implicit learning is the process through which we become sensitive to certain regularities in the environment, in the absence of the intention to learn about these same regularities and in such a way that the resulting knowledge is difficult to express. In other words, implicit learning refers to the incidental or casual, and sometimes seemingly small, acquisition of a given event. It can generate significant future consequences. ${ }^{42}$

Few articles assessed Language, ${ }^{14,35,37}$ Attention, ${ }^{23}$ Perception $^{35}$ and Visuospatial Skills. ${ }^{27,36}$ One study ${ }^{43}$ reported PD patients without dementia who exhibited impairment in verbal comprehension, grammatically complex sentence identification, repetitive speech, decreased abstraction capacity, slow processing speed and attention deficit. ${ }^{44}$ There is greater impairment in naming ability and verbal fluency. ${ }^{8}$ Language difficulties may be related to EF, which plays an important role in language. We also found difficulties in understanding grammatically complex sentences, disorders involving communication and repetitive speech. ${ }^{44}$ Attention is impaired in $\mathrm{PD}$, causing reduction of latency in simple and choice reaction times. After dopamine replacement, there is an improvement in the identification of stimuli. ${ }^{40}$ Regarding Visuospatial and Perception skills, these require the recruitment of certain subcortical structures, in addition to the occipital, parietal and frontal lobes. ${ }^{45}$ Deficits in this function in PD correlate with postural instability and gait difficulty. ${ }^{44}$ Sensory-motor coordination also had only 2 instruments for its evaluation..$^{14,20}$

Only 3 articles ${ }^{20,31,38}$ used instruments to assess psychiatric symptoms in PD (PANDA, BPRS and Visual Analogue Mood Scale). Some authors ${ }^{46}$ investigated the existence of information on various psychiatric conditions in patients with PD and found that more than 50\% of non-motor symptoms are not identified in clinical practice. They observed the prevalence of depression ( $2 \%$ - 31\%), psychosis (15\% - 75\%), anxiety (19\% - 67\%), sleep disorder $(15 \%$ - $87 \%)$ and cognitive deficits (MCI $18 \%-55 \%$ and dementia 31\%), among others. Psychiatric symptoms were associated with the stage of PD and cognitive impairment of the patient, but not with age, duration of illness, levodopa dose or 'ON' or 'OFF' stage. Although common, psychiatric changes in PD are not criteria for clinical diagnosis. ${ }^{47}$ These changes can become more disabling than motor deficits and may be a consequence of complications of the pharmacological treatment for the motor symptoms of the disease or as an integral part of the PD clinical manifestations. ${ }^{48}$

Only 2 scales were used for assessing PD Quality of Life (QoL): PDQ-3949 and PDQL..$^{50}$ Regarding mood, several scales were used, with use of depression inventory being the most often cited. ${ }^{14,20,21,23,25,27,32,36,37}$ Together with the QoL scales, these instruments enable a more in-depth examination of the individual and impacts of the disease on their life.

Some of the limitations of the study were the instruments used at different stages of the studies, albeit for the inclusion and/or exclusion criteria and during the pre and post-operative evaluation of patients. Besides the large diversity of instruments, other aspects such as version, validation and cut-off points were also heterogeneous.

The instruments used before and after DBS implantation to assess the cognitive aspects of patients are shown in Table 3. Generically speaking, we could consider them as a possible battery for evaluating the effects of surgery. The literature has shown that most authors consider these instruments sufficient to identify the patient's diagnostic profile. These aspects are extremely relevant to analyze the results of a study. Differences in each of them may engender results that differ from those expected. These changes range from severely compromised to slightly compromised. Another example is the use of tailored tasks, Verbal Fluency Tasks ${ }^{13,14,16-18,20,21,23,26,27,29,30,32,34-36,38}$ the n-back task and dual task ${ }^{51}$ rather than standardized tests, such as the Wechsler Adult Intelligence Scale ${ }^{27,35}$ and Hooper Visual Organization Test. ${ }^{36}$

The results of this review point to the absence of a specific assessment protocol for PD with STN-DBS, revealing extensive variability of instruments used in different studies. However, analysis of each methodology yielded a possible battery for investigating the effects of surgery based on the frequency of use of instruments in the studies. The feasibility of using this battery and its findings should be the focus of future studies to establish a standard for assessment.

Authors contributions. Eduarda Naidel Barboza e Barbosa: study concept and design, literature search, drafting and revising the manuscript; Helenice Fichman: contribution during the writing process with suggestions and corrections. 


\section{REFERENCES}

1. Pavão R. Aprendizagem Implícita e Doença de Parkinson. Dissertação de mestrado - Instituto de Biociências da Universidade de São Paulo. Departamento de Fisiologia, 2007.

2. de Paixão AO, de Jesus AVF, Silva FS, Messias GMS, Nunes TLGM, Nunes TLGM, Santos TB, Gomes MZ, Correia MGS. Doença de Parkinson: Uma Desordem Neurodegenerativa. Cadernos de Graduação - Ciências Biológicas e da Saúde. 2016; 1(16):57-65.

3. Machado FA, Reppold CT. The effect of deep brain stimulation on motor and cognitive symptoms of Parkinson's disease - A literature review. Dement Neuropsychol. 2015;9(1):24-31.

4. Werneck ALS. Doença de Parkinson: Etiopatogenia, Clínica e Terapêutica. Rev Hosp Univ Pedro Ernesto. 2010;9:10-9.

5. Heluani, AS. Cognição, humor e atividades funcionais em pacientes com doença de Parkinson submetidos à estimulação cerebral profunda bilateral em núcleo subtalâmico. Dissertação de mestrado - Faculdade de Medicina da Universidade de São Paulo, 2014.

6. Nombela C, Rowe JB, Winder-Rhodes SE, Hampshire A, Owen AM, Breen $\mathrm{DP}$, et al. Genetic impact on cognition and brain function in newly diagnosed Parkinson's disease: ICICLE-PD study. Brain. 2016;137: 2625-31.

7. Ding W, Ding LJ, Li FF, Han Y, Mu L. Neurodegeneration and cognition in Parkinson's disease: a review. Eur Rev Med Pharmacol Sci. 2015;19: 2275-81.

8. Aguilar OM, Soto CA, Esguerra M. Cambios neuropsicológicos asociados a estimulación cerebral profunda en enfermedad de parkinson: revisión teórica. Suma Psicológica. 2011;18(2):89-98.

9. Stella F, Gobbi LTB, Gobbi S, Oliani MM, Tanaka K, Pieruccini-Faria F. Early impairment of cognitive functions in Parkinson's disease. Arq Neuropsiquiatr. 2007;65(2b):406-10.

10. Schneider JS, Sendek S, Yang C. Relationship between Motor Symptoms, Cognition, and Demographic Characteristics in Treated Mild/ Moderate Parkinson's Disease. PLoS One. 2015;10(4):1-11.

11. de Oliveira MD, Machado DMS. Cognitive decline in Parkinson's disease: contributions of Neuropsychology. Rev Med Minas Gerais. 2015;24(3): 349-54.

12. Lang AE, Lozano AM. Parkinson's disease. First of two parts. New England J Med. 1998;339(15):1044-53.

13. Cilia R, Siri C, Marotta G, Gaspari D, Landi A, Mariani CB, Benti R, Isaias $I U$, Vergani F, Pezzoli G, Antonini A. Brain networks underlining verbal fluency decline during STN-DBS in Parkinson's disease: An ECD-SPECT study. Parkinson Relat Disord. 2007;13(5):290-4.

14. Heo JH, Lee KM, Paek SH, Kim MJ, Lee JY, KimJY, et al. The effects of bilateral Subthalamic Nucleus Deep Brain Stimulation (STN DBS) on cognition in Parkinson disease. J Neurol Sci. 2008;273(1):19-24.

15. Lueken U, Schwarz M, Hertel F, Schweiger E, Wittling W. Impaired performance on the Wisconsin Card Sorting Test under left- when compared to right-sided deep brain stimulation of the subthalamic nucleus in patients with Parkinson's disease. J Neurol. 2008;255(12):1940-8.

16. Zangaglia R, Pacchetti C, Pasotti C, Mancini F, Servello D, Sinforiani $\mathrm{E}$, et al. Deep brain stimulation and cognitive functions in Parkinson's disease: A three-year controlled study. Mov Disord. 2009; 24(11):1621-8.

17. York MK, Wilde EA, Simpson R, Jankovic J. Relationship between neuropsychological outcome and DBS surgical trajectory and electrode location. J Neurol Sci. 2009;287(1):159-71.

18. Fasano A, Romito LM, Daniele A, Piano C, Zinno M, Bentivoglio AR, Albanese A. Neuropsychological changes 1-year after subthalamic DBS in PD patients: A prospective controlled study. Brain. 2010; 133(9):2664-76

19. Van Wouwe NC, Ridderinkhof KR, Van Den Wildenberg WP, Band GP, Abisogun A, Elias WJ, et al. Deep Brain Stimulation of the Subthalamic Nucleus Improves Reward-Based Decision-Learning in Parkinson's Disease. Front Hum Neurosci. 2011;5:30.

20. Israeli-Korn S, Hocherman S, Hassin-Baer S, Cohen O, Inzelberg R. Subthalamic Nucleus Deep Brain Stimulation Does Not Improve VisuoMotor Impairment in Parkinsons Disease. PLoS One. 2013;8(6):e65270.

21. Kim HJ, Jeon B, Yun J, Kim Y, Yang HJ, Paek S. Initial cognitive dip after subthalamic deep brain stimulation in Parkinson disease. J Neurol. 2013;260(8):2130-3.

22. Asahi T, Nakamichi N, Takaiwa A, Kashiwazaki D, Koh M, Dougu N, et al. Impact of bilateral subthalamic stimulation on motor/cognitive functions in Parkinson's disease. Neurol Med Chirurg. 2014;54(7):529-36.
23. Rizzone MG, Fasano A, Daniele A, Zibetti M, Merola A, Rizzi L, et al. Long-term outcome of subthalamic nucleus DBS in Parkinson's disease: From the advanced phase towards the late stage of the disease? Parkinson Relat Disord. 2014;20(4):376-81.

24. Markser A, Maier F, Lewis C, Dembek T, Pedrosa D, Eggers C, Timmermann L, Kalbe E, Fink G, Burghaus L. Deep brain stimulation and cognitive decline in Parkinson's disease: The predictive value of electroencephalography. J Neurol. 2015;262(10):2275-84.

25. Krishnan S, Prasad S, Pisharady K, Sarma G, Sarma S, Kishore A. The decade after subthalamic stimulation in advanced Parkinson's disease: A balancing act. Neurol India. 2016;64(1):81.

26. Klempírová O, Jech R, Urgosík D, Klempír J, Spacková N, Roth J, Růzicka E. Deep brain stimulation of the subthalamic nucleus and cognitive functions in Parkinson's disease. Prague Med Rep. 2007;108(4): 315-23.

27. Witt K, Daniels C, Reiff J, Krack P, Volkmann J, Pinsker MO, et al. Neuropsychological and psychiatric changes after deep brainstimulation for Parkinson's disease: a randomised, multicentre study. Lancet Neurol. 2008;7(7):605-14.

28. Hariz M. Deep brain stimulation plus best medical therapy versus best medical therapy alone for advanced Parkinson's disease. Lancet Neurol. 2009;8(3):223-4.

29. Daniels C, Krack P, Volkmann J, Pinsker MO, Krause M, Tronnier V, et al. Risk factors for executive dysfunction after subthalamic nucleus stimulation in Parkinson's disease. Mov Disord. 2010;25(11):1583-9.

30. Houvenaghel JF, Jeune F, Dondaine T, Esquevin A, Robert G, Péron J, et al. Reduced Verbal Fluency following Subthalamic Deep Brain Stimulation: A Frontal-Related Cognitive Deficit? PLoS One. 2015;10(10): e0140083.

31. Pham UHG, Andersson S, Toft M, Pripp AH, Konglund AE, Dietrichs E, et al. Self-Reported Executive Functioning in Everyday Life in Parkinson's Disease after Three Months of Subthalamic Deep Brain Stimulation. Parkinsons Dis. 2015;2015:461453.

32. Castelli L, Lanotte M, Zibetti M, Caglio M, Rizzi L, Ducati A, et al. Apathy and verbal fluency in STN-stimulated PD patients. J Neurol. 2007; 254(9):1238-43.

33. Barbosa ENB, Charchat-Fichman H. (Advisor). Neuropsychological assessment contribuition to Mild Cognitive Impairment (MCl): methodological issues. Rio de Janeiro, 2015. 144p. MSc. Dissertation - Psychological Departament, Pontifícia Universidade Católica do Rio de Janeiro.

34. Castelli L, Rizzi L, Zibetti M, Angrisano S, Lanotte M, Lopiano L. Motor and cognitive outcome in patients with Parkinson's disease 8 years after subthalamic implants. Parkinson Relat Disord. 2010;16(2):115-18.

35. Yágüez L, Costello A, Moriarty J, Hulse N, Selway R, Clough C, et al. Cognitive predictors of cognitive change following bilateral subthalamic nucleus deep brain stimulation in Parkinson's disease. J Clin Neurosci. 2014;21(3):445-50.

36. Tang V, Zhu C, Chan D, Lau C, Chan A, Mok V, et al. Evidence of improved immediate verbal memory and diminished category fluency following STN-DBS in Chinese-Cantonese patients with idiopathic Parkinson's disease. Neurol Sci. 2015;36(8):1371-7.

37. Tremblay C, Macoir J, Langlois M, Cantin L, Prudhomme M, Monetta L. The effects of subthalamic deep brain stimulation on metaphor comprehension and language abilities in Parkinson's disease. Brain Lang. 2015; 141:103-9.

38. Vonberg I, Ehlen F, Fromm O, Kühn A, Klostermann F. Deep Brain Stimulation of the Subthalamic Nucleus Improves Lexical Switching in Parkinsons Disease Patients. PLoS One. 2016;11(8):e0161404

39. Lourenço RA, Veras RP, Ribeiro PCC. Confiabilidade teste-reteste do mini-exame do estado mental em uma população idosa assistida em uma unidade ambulatorial de saúde. Rev Bras Geriatr Gerontol. 2008; 11:7-16.

40. Macuglia GR, Rieder CRM, de Almeida RMM. Funções executivas na doença de Parkinson: Revisão da Literatura. PSICO. 2012;43(4):552-61.

41. Ventre-Dominey J, Mollion H, Thobois S, Broussolle E. Distinct effects of dopamine vs STN stimulation therapies in associative learning and retention in Parkinson disease. Behav Brain Res. 2016;302:131-41.

42. Rita HJP, Reis Al. (Advisor) Dissociação da memória explícita e implícita da Doença de Parkinson. MSc. Dissertation - Human Sciences and Social College. Universidade do Algarve. 2012. 
43. Poliakoff E, Smith-Spark JH. Everyday cognitive failures and memory problems in Parkinson's patients without dementia. Brain Cogn. 2008; 67(3):340-50.

44. Melo LM, Barbosa ER, Caramelli P. Declínio cognitivo e demência associados à doença de Parkinson: características clínicas e tratamento. Rev Psiquiatr Clín. 2007;34(4):176-83.

45. Galhardo MMAMC, do Amaral AKFJ, Vieira ACC. Caracterização dos distúrbios cognitivos na Doença de Parkinson. Revista CEFAC. 2009;11(2):251-7.

46. Grover S, Somaiya M, Kumar S, Avasthi A. Psychiatric aspects of Parkinson's disease. J Neurosci Rural Pract. 2015;6(1):65-76.

47. Aarsland D, Larsen JP, Lim NG, Janvin C, Karlsen K, Tandberg E, Cummings JL. Range of neuropsychiatric disturbances in patiens with Parkinson's disease. J Neurol Neurosurg Pshychiatry. 2009;67: 492-6.

48. Junior AS, Cabral ACJ. Alterações Psiquiátricas na Doença de Parkinson. In Forlenza, OV; Caramelli, P. Neuropsiquiatria geriátrica. São Paulo: Editora Atheneu; 2000.

49. Chrischilles EA, Rubenstein LM, Voelker MD, Wallace RB, Rodnitzky RL. Linking clinical variables to health-related quality of life in Parkinson's disease. Parkinson Relat Disord. 2003;8:199-209.

50. De Boer AGEM, Spruijt RJ, Sprangers MAG, de Haes JCJM. Diseasespecific quality of life: is it one construct? Qual Life Res. 1998;7:135-42.

51. Alberts JL, Voelcker-Rehage C, Hallahan K, Vitek M, Bamzai R, Vitek JL. Bilateral subthalamic stimulation impairs cognitive-motor performance in Parkinson's disease patients. Brain. 2008;131(12):3348-60. 